\title{
Gordon syndrome
}

INSERM

\section{Source}

INSERM. (1999). Orphanet: an online rare disease and orphan drug data base. Gordon syndrome. ORPHA:376

Gordon syndrome, also known as distal arthrogryposis type 3, is an extremely rare multiple congenital malformation syndrome characterized by congenital contractures of hand and feet with variable degrees of severity of camptodactyly, clubfoot and, less frequently, cleft palate. Intelligence is normal but in some cases, additional abnormalities, such as short stature, kyphoscoliosis, ptosis, micrognathia, and cryptorchidism may also be present. Gordon syndrome, Marden-Walker syndrome and arthrogryposis with oculomotor limitation and electroretinal anomalies clinically and genetically overlap, and could represent variable expressions of the same condition. 